\title{
Džässi ja rahvamuusika suhetest Eestis 20. sajandi I poolel
}

Tiit Lauk

Teesid: Käesolevas artiklis käsitletakse afro-ameerika päritolu džässmuusika jõudmist meie kultuuriruumi ja sellega kaasnenud nähtusi, keskendudes džässi ja eesti rahvakultuuri vastastikustele mõjutustele. Uurimus lähtub faktist, et vaid kümmekond aastat pärast Eestimaale jõudmist, s.o juba 1930. aastate algul püüti meie rahvamuusikast vägagi erinevat džässmuusikat mängida külakapellidega. Tekkinud külakapellide ja džässi seoseid vaadeldakse mitme akulturatsiooniteooria seisukohalt, võttes käsitluse lähtepunktiks siinkirjutaja arusaamisel ja pikaaegsel kogemusel põhineva määratluse džässmuusika põhiolemusest. Andmete analüüsi tulemusena jõutakse seisukohale, et eelkirjeldatud nähtust ei ole meil veel põhjust pidada rahvuslikuks džässiks.

Märksõnad: akulturatsioon, džäss, haitarijazz, külajäts, külakapellid, sving, The Murphy Band

Selle teema käsitlemist peaks alustama küsimusega, mis on džäss. Selline küsimus võib tunduda praegu, 21. sajandi hakul imelikuna, sest oleme ju ammu harjunud pidama džässmuusikat meie kultuuripildi iseenesestmõistetavaks osaks. Ometi vaieldakse selle üle siiani, ja ühest, kõigi poolt tingimusteta aktsepteeritud definitsiooni pole veel sõnastatud. Seda probleemi käsitleb põhjalikult ka muusikateadlane William Howard Kenney oma ulatuslikus artiklis "Context and Definition of Jazz" (Kenney 1995: 100-116), tuues hulga näiteid, definitsioonini ikkagi jõudmata. Teadaolevalt esimene katse džässi defineerida ilmus 1914. aastal San Francisco Bulletinis:

Anything that takes mainliness or effort or energy or activity or strength of soul is jaz [Kõik, mis kasutab hinge voolusängi või pingutust (ponnistust) või energiat või aktiivsust või jõudu ongi džäss] (Porter \& Ullman \& Hazel 1992: 5).

Nagu väidab Joachim-Ernst Berendt, ${ }^{1}$ pole üheski teises kunstiliigis viiekümne aasta jooksul välja kujunenud niivõrd kontrastseid, kuid siiski omavahel tihedalt seotud stiilivoole, kui džässis (Berendt 1999: 16). Tegelikult on paari 
lausesse peaaegu võimatu kokku võtta kogu seda tohutut erinevate stiilide mitmekesisust laial skaalal ragtime'ist kuni avangardismini. Tundub, et definitsiooni sõnastamine ongi kujunenud rohkem muusikakriitikute, produtsentide ja ajakirjanike kui tegevmuusikute probleemiks. Selles kontekstis tsiteeritakse sageli Duke Ellingtoni, ${ }^{2}$ kes on öelnud:

If jazz means anything at all, which is questionable, it means the same things to musicians fifty years ago - freedom of expression [Kui (sõna) džäss üldse midagi tähendab, mis on küsitav, oli tema tähendus muusikuile viiskümmend aastat tagasi sama - vabadus end väljendada] (O’Meally 1998: 5).

Seda maestro Ellingtoni mõtteavaldust tuleks mõista ilmselt nii, et sõna jazz on sümbol, mis tähistab üht kindlat nähtust muusikamaailmas, mille tähendus muusikuile on algusest peale püsinud muutumatuna ja mille defineerimisel pole muusikute silmis mingit tähtsust. Louis Armstrong on näiteks öelnud: Mis on džäss? Kui sa pead seda küsima, ei saa sa seda kunagi teada (Luts 2006: 103).

Kuidagi peame aga selle nähtuse põhiolemuse käesolevas artiklis lühidalt edasi andma, sest nagu ütleb austria filosoof, näitleja, kirjanik ja teatrikriitik Egon Friedell (1878-1938):

Kõik klassifikatsioonid, mida inimene kunagi on teinud, on sihilikud, kunstlikud ja valed. Aga samas on nad vajalikud ja vältimatud, kuna vastavad meie mõtlemise sünnipärasele kalduvusele (Berendt 1999: 11).

Pakun siinkohal välja variandi, mis on küll pisut üldsõnaline, kuid ei tohiks millegi vastu eksida: džäss on 20. sajandi algul euroopaliku ja aafrikaliku muusikakultuuri segunemisel Ameerikas tekkinud improvisatsioonil põhinev muusikažanr, millele on iseloomulik eriline rütmiline intensiivsus ehk svingimine ${ }^{3}$ ja stiilide rohkus. Siinjuures tuleb kindlasti arvesse võtta asjaolu, et oma arengu esimese kolmekümne aasta jooksul oli džäss valdavalt tantsumuusika. Kuigi Paul Whiteman ${ }^{4}$ otsis juba 1920. aastail võimalusi džässi kontserdilavale toomiseks, on esimesed akadeemilises mõistes kontserdid teada siiski alles 1930. aastast.

Käesolev artikkel hõlmab väheuuritud lõiku Eesti kultuuriloos - džässmuusika jõudmist meie kultuuriruumi ja sellega kaasnenud nähtusi, keskendudes džässi ja eesti rahvakultuuri vastastikustele mõjutustele. Selline teemaasetus ei ole võõras ka teistele rahvastele - oma ilmumisest alates on džäss tekitanud siin ja seal vastakaid arvamusi vaimustusest kuni täieliku eitamise ja ärakeelamiseni. Sellest hoolimata tuleb tunnustada uue kultuuriilmingu vitaalsust ja levimisvõimet, mis seostub omakorda tema pideva arenemis- ja kohanemis- 
võime ning vastuvõtlikkusega uutele ideedele. Jälgides džässi levikut, torkab silma teatud territoriaalsuse printsiip - kuigi tema leviku algpunktideks olid valdavalt elavama kultuurieluga suurlinnad (Pariis, London, Berliin, meie kontekstis Tallinn), toimus edasine levik siiski suurel määral riigipiire arvestavalt ehk territoriaalselt. See on ka täiesti loogiline, sest igal riigil ja rahvusel on oma kultuuritraditsioonid, mis mõjutavad kõige otsesemalt ka sissetungija saatust. Mõnel pool on ta teretulnud, mõnel pool aga osutub tõrjutuks. ${ }^{5}$ Sellest lähtuvalt jagunevad ka džässist kirjutatud uurimused kaheks suureks rühmaks: ühed käsitlevad džässi kui nähtust, pööramata mingit tähelepanu muusikute rahvusele või päritolumaale, teised pööravad põhitähelepanu just džässi arengule mingi kitsama territooriumi/riigi piires. Praeguseks on džässist kirjutatud sadu uurimusi. Esimese valdkonna uurimusi on kahtlemata tunduvalt rohkem, džässi on analüüsinud nii Frankfurdi koolkonna filosoofid eesotsas Theodor Adornoga (1903-1969) kui ka muusikateoreetikud alates Ernest Ansermetist (1883-1969) ja Robert Goffinist (1898-1984). ${ }^{6}$ Teise valdkonna vastu on suuremat huvi üles näidanud just väiksemate rahvuste, näiteks Soome (Jalkanen 1989, Haavisto 2000) ja Rootsi (Bruér 1998) esindajad, Rootsi Džässiföderatsiooni egiidi all tegutseb rootsi džässiajaloo komisjon.

Teadaolevatel andmetel jõudis džässmuusika küllaltki tugeva (balti)saksa ja vene mõjutustega eesti kultuuripilti eelmise sajandi teisel kümnendil uute moetantsude cakewalk, onestep ja two-step saatemuusikana. Seega toimus afroameerikalikku päritolu kultuuriilmingu invasioon meie niigi mitmetest välismõjudest küllastunud soome-ugrilikku kultuuriruumi. Siin tekibki kohe küsimus, kas uustulnuk oli siin teretulnud või osutus tõrjutuks? Kas see jäi omaette eksisteerivaks nähtuseks, või hakkas kuidagimoodi sulanduma meie traditsioonilisse kultuuri? Või ehk oleks põhjust rääkida koguni rahvusliku džässi esimestest ilmingutest? Ehk siis millisesse akulturatsiooni staadiumisse džässi sissemurre meil II maailmasõja eel jõudis?

Nagu eelnev lause juba viitab, on uurimuse aluseks võetud teooriad, mis käsitlevad akulturatsiooni toimemehhanisme ja millele toetudes on uuritud muutusi muusikas, sh džässi levikut, mitmetes teisteski Euroopa riikides, näiteks Soomes. Teatavasti andsid olulise panuse kõnesolevate teooriate rakendamisse etnomusikoloogias Alan P. Merriam, Bruno Nettl, Klaus P. Wachsmann, Peter Murdock, Wolfgang Laade jt. Nagu viitab Soome muusikateadlane ja džässiuurija Pekka Jalkanen, toetub Laade teooria Die Probleme der musikalischen Akulturation suurel määral USA etnomusikoloogia klassikute Mellville J. Herskovitsi, Richard Watermanni ja eelmainitute ideedele. Nii näeb P. Murdock akulturatsiooniprotsessi nelja-faasilisena: innovatsioon, sotsiaalne heakskiit, valikuline elimineerimine, integratsioon (Murdock 1960), Laade soovitab käsitleda sama protsessi viie-faasilisena: valik, omaksvõtt ja integ- 
reerimine, tasakaalustamine, tõrjumine, ühtimine. Bruno Nettl väidab, viidates siin ka Klaus P. Wachsmanni ja Alan P. Merriami töödele, et akulturatsioonialased uurimused, mis on naaberkultuuride vahelise lähema kontakti tulemus, on tekkinud just muusika kaudu (Nettl 1964: 4). Nagu viitab P. Jalkanen, on etnomusikoloogia teooria olnud kaua antropoloogilise teooria muusikauurimuste alale sobitaja rollis. Selle järgi on muusika muutumine määratletud kahe kultuuri iseenesliku leviku ja akulturatsiooni ilminguks, arenguetapiks, millele paneb aluse kultuuri seest- või väljastpoolt tulnud innovaatiline alge (innovation) (Jalkanen 1989: 9). Peter Murdock on väitnud oma 1965. aastal ilmunud uurimuses "How Culture Changes":

Muutused sotsiaalses käitumises ja kultuuris lähtuvad tavaliselt tähendusrikastest muutustest ühiskonnas (Murdock 1965: 116).

Wolfgang Laade rõhutab, et akulturatsiooni toimumiseks peab olema piisavalt aega; sellele eelneb tavaliselt nn inkupatsiooniperiood. Et antud juhul ei ole tegemist naaberkultuuridega, vaid meile kauge afro-ameerikaliku džässkultuuri invasiooniga, ei pruugi kõik eelmainitud teooriate käsitlused siia sobida. Nagu märgib Pekka Jalkanen (Jalkanen 1989: 12), on Murdocki kultuurimuutuste teooria staatilisem kui Laade teooria, see-eest lähtub Murdock rohkem muusikast kui antropoloogiast ja on Jalkaneni hinnangul seega džässkultuuri arengu analüüsimiseks kohasem.

Sobiva kultuurimuutuste teooria valikus oli niisiis mitu võimalust. Jagan täielikult Jalkaneni arvamust, et džässi arengute jälgimiseks sobib kõige paremini nn kultuurileviku käsitlus. Antropoloogilisest küljest oleks see akulturatsiooni alaliik ja tähistaks eriliselt valivat akulturatsiooni, kus vana ja uue ainese vahel tekitatakse tasakaal, mille tulemusel sünnib uus kultuuritüüp (Jalkanen 1989: 13).

Kuna olukord Eesti ja Soome kultuuriruumis oli vaadeldaval ajal (20. sajandi I poolel) suhteliselt sarnane, on ka käesoleva artikli teoreetiline lähtekoht valitud samadel kaalutlustel.

\section{Džäss jõuab Eestisse}

Ajaliselt langes džässi saabumine Eestimaale uuteks arenguteks väga soodsale hetkele - riik ja rahvas olid äsja vabanenud oma suure naabri võimu alt ja seega oli täiesti loomulik ka soov vabaneda kiiresti poliitika dikteeritud kultuurilistest surutistest. Teisest küljest aga, nagu kirjutab ka Soome ajaloolane Kalervo Hovi (Hovi 2002: 13), tingis seesama ajaloohetk ka niigi marginaalse argielu, mille alla džäss tantsumuusikana kuulus, veelkordse marginalisee- 
rumise. Selle mitmekordse marginaalsuse tõttu kohtame ka olulisi takistusi uurimise teel - ajakirjanduses ilmus väga vähe kirjutisi džässmuusikast ja neis vähesteski torkab sageli silma kirjutaja ebakompetentsus; korraliku kriitika ja analüüsi vääriliseks meil džässi, kui tantsumuusikat ei peetud. Esimese teadaoleva katse seda uut muusikat Eestis mängida tegid Tallinna Peetri Reaalkooli poisid 1918. aasta suvel, millest Kurt Strobel jutustab värvikalt oma elulookassetil. ${ }^{7}$ Nendeks olid Kurt Strobel ja Herbert Putzker viiulitel ja Konstantin Paalse (tookord Paulson) klaveril. Peagi tulid juurde viiuldajad Rolf Eichwald ja Alfred Klas-Glas ning Eduard Klas-Glas ${ }^{8}$ tšellol, Strobel vahetas aga viiuli trummide vastu. Strobeli andmeid kinnitab ka teine selle grupi liige Konstantin Paalse, kelle 1970. aastal antud intervjuust Valter Ojakäärule saame teada ka nende esimese avaliku esinemise koha - selleks oli hotell Kommerz, mis asus samas majas, kus poisid proovi tegid ja mille peremees kutsus neid oma külalistele mängima (Ojakäär 2000: 79-80). Algul areneski džäss põhiliselt Tallinnas ja 1925. aasta suvel alustas kohvikus Marcelle ${ }^{9}$ tööd Eesti esimene kutseline džässorkester The Murphy Band. Orkestri tuumikusse kuulusid eelmainitutest Kurt Strobel (trummid), Rolf Eichwald (viiul) ja Konstantin Paalse $^{10}$ (bandžo), neile lisandusid koolivend Wolfgang Pachla (klaver), Strobeli onupoeg Eugen Allas (bandžo, hiljem saksofon) ja endine sõjaväeorkestrant Jakov Zahharov (trompet). Sügisel ühines bändiga Victor Compe, ${ }^{11}$ kes vahetas välja algaja pianisti Pachla ja kellest, kui kõige kogenumast, sai ka orkestri kunstiline juht. Seega kulus esimestest katsetustest arvestatavale professionaalsele tasemele jõudmiseks seitse aastat. Väidet, et The Murphy Band oli saavutanud hea professionaalse taseme, tõestab nende kaheksa kuu pikkune tööreis Saksamaale 1927. aastal. Esinedes Berliinis, Cottbusis, Rostockis ja Dresdenis mängisid nad nii tantsumuusikat kui saatsid ka nõudlikke varieteeprogramme. Dresdenis esinesid nad lokaalis Tanzplast Libelle vaheldumisi Ameerika orkestriga, kellega mingit märgatavat tasemevahet polnud (Ojakäär 2000: 111-112). Edasine areng oli üsnagi tormiline: järgmise 15 aasta jooksul on Tallinnas tegutsenud umbes 60 džässilikku tantsumuusikat viljelenud orkestrit (sh restoranide orkestrid) rohkem kui 400 muusikuga.

Džässi teistesse Eestimaa linnadesse jõudmise aega on peaaegu võimatu täpselt tuvastada, oletatavasti toimus see umbes $5-8$ aastat hiljem kui Tallinnas, ja pole üldse kindel, millal kohalikud arengud niikaugele jõudsid, et seda võiks kasvõi tinglikult nimetada džässiks. Ei maksa unustada, et džäss oli moes, ja alati on neid, kes on reklaami huvides valmis ehtima end võõraste sulgedega, sõltumata sellest, kas selleks mingit alust on või mitte. Mingi tõenäosuse saamiseks on siiski vajalik analüüsida olemasolevaid andmeid.

Vaadates Eesti džässbändide teket kajastavat kaarti (vt joonis 1), äratab tähelepanu Tallinna ja Tartu - Viljandi - Pärnu mõttelise joone vahel laiuv 


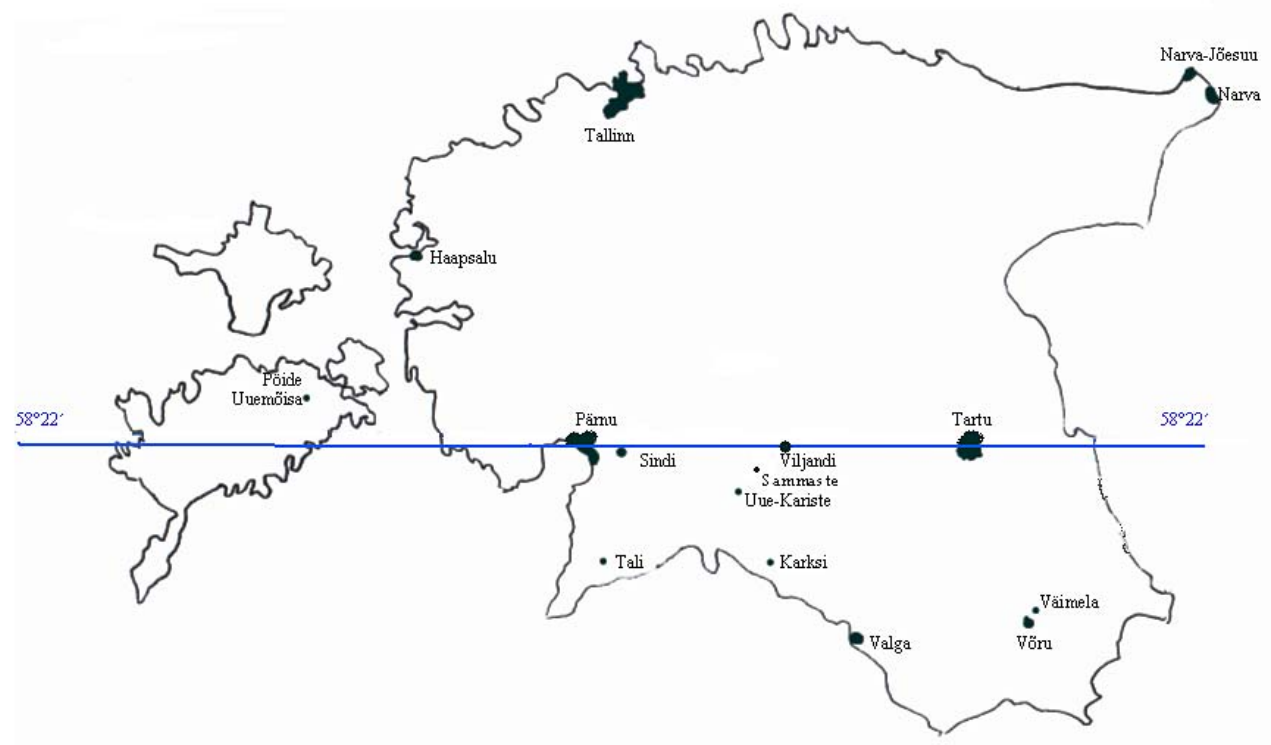

Joonis 1. Džässilike tantsuorkestrite tekkimise kaart.

rohkem kui poole Eesti suurune tühi ala. Sellelt suurelt alalt Põhja- ja KeskEestis, mille lõunapiir ühtib geograafilise 58²2' laiuskraadiga, ei ole, hoolimata sellest, et sinna jäid muidu üsna elava kultuurieluga suuremad keskused Rapla, Tapa, Rakvere, Türi, Paide, Suure-Jaani ja Jõgeva, õnnestunud leida ühtegi jälge džässmuusika levikust kahe maailmasõja vahel. Ainsa erandina on andmeid Kukruse jazzbandist 1938. aastast. ${ }^{12}$ Ühest küljest on džässilike kollektiivide puudumist nii suurel alal raske mõista, teades, et tantsukursused olid populaarsed ka Kesk-Eestis, ${ }^{13}$ st info sellisest tantsumuusikast oli kursuste vahendusel ka sinna jõudnud.

Loogiline oleks arvata, et suuremates keskustes, kus tegutsesid arvestatava tasemega puhkpilliorkestrid, eksisteerisid nende juures ka väiksemad tantsumuusika-koosseisud. Teisest küljest teame, et paljud haritud muusikaõpetajad ja orkestrijuhid suhtusid džässmuusikasse eelarvamusega ega soovinud/ osanud seda mängida, pärssides oma autoriteediga kõik tagasihoidlikumadki katsetused. Nagu näeme kõikide väikestes kohtades tekkinud džässbändide puhul, on määravaks osutunud aktiivse eestvedaja olemasolu, sellise puudumisel on läbi aetud naabritelt tellitud orkestritega. ${ }^{\mathbf{1 4}}$

Jääb loota, et edaspidi õnnestub leida rohkem dokumente, mis aitaksid sellele küsimusele täpsemalt vastata. 
Džässilike tantsuorkestrite tekkimise geograafiat vaadeldes torkab silma suurem orkestrite kontsentratsioon Lõuna-Eestis, eriti Mulgimaal. Sellel saab olla kaks loogilist põhjust: esiteks tundub, et Tallinn oma suuruse ja aktiivse džässieluga pärsib kõik sellelaadsed arengud rohkem kui saja kilomeetri raadiuses enda ümber, imedes käsnana endasse kõik andekamad džässihuvilised noored. Teisele võimalikule põhjusele viitab Herbert Tampere, kelle andmetel oligi ansamblimäng rohkem arenenud just Lõuna-Eestis (Tampere 1975: 43). Tundub, et ka siin toimib eelmainitud territoriaalsuse printsiip.

\section{Džässi ja rahva(liku)muusika sümbioos}

Uurides lähemalt džässmuusika levikut Lõuna-Eestis sattusin huvitavale nähtusele, mida meie muusikaajaloo uurijad siiani käsitlenud ei ole. Nagu selgub, on mitmel pool Tartu-Viljandi-Pärnu mõttelisest joonest lõunasse jääval alal (erandina ka Saaremaal Pöide-Uuemõisas) püütud mängida džässi külakapellidega. See viitab akulturatsiooniprotsessi käivitumisele selles piirkonnas kohaliku rahva(liku)muusika ja meie kultuuriruumi sissetungijana ilmunud afroameerikalikku päritolu džässmuusika vahel. Selle nähtuse erakordsuse mõistmiseks vaadakem kõigepealt, millist ansamblitüüpi on meil harjutud külakapelliks nimetama.

Igor Tõnuristi uurimusest "Koosmäng eesti rahvapillimuusikas" (Tõnurist 1996: 82) selgub, et ansamblimängu traditsioon meie rahvamuusikas ei ole kuigi vana - pole isegi koosmängu tähistavat rahvapärast terminit. Nagu kirjutab meie rahvamuusika suurimaid autoriteete Herbert Tampere, on rahvapilliansamblite kohta varasematest aegadest väga vähe andmeid, teadaolevalt esimene kirjalik märge ansamblite eksisteerimisest eestlaste musitseerimises pärineb aastast 1765, mil Tartu raad lubas oma pulmamääruses eestlastel sel puhul muusikat teha kahe viiuli ja torupilliga (Tampere 1975: 41). I. Tõnurist juhib oma eelmainitud artiklis tähelepanu asjaolule, et meie rahvamuusika kujunemise omapäraks 19. ja 20. sajandi vahetusel oli tõik, et meie koolilastel oli sageli võimalus omandada viiulimängu- ja noodilugemisoskus rahvakoolides, mis soodustas viiulimängu erakordset populaarsust rahva seas, orkestrimänguga tutvumine oli aga otseseks tõukeks ja eeskujuks paljude rahvapäraste instrumentaalansamblite tekkimisel. Lisaks viiulile muutusid eelmise sajandi algul populaarseks kitarrid ja mandoliinid. Need pillid võeti kasutusse esmajoones seoses vaimuliku, aga ka sentimentaalse ilmaliku musitseerimisega (Tõnurist 1996: 50).

Eriti palju uuendusi tõid külamuusikasse Esimese maailmasõja järgsed aastad. Laialt levis uus pill akordion, tuntuks said havai kitarr ja bandžo, kõik 
need lülitati ka külakapellidesse. Uute tantsude (tango, foks) levikuga laienes tunduvalt ka külakapellide repertuaar (Tõnurist 1996: 82). Kuna samal ajal oli tekkinud ka arvukalt puhkpilliorkestreid, kasutati külakapellides tihtilugu sealt pärit pille (trompet, klarnet, trumm), millest tulenevalt kujunes nende kapellide koosseis üsna kirjuks. Tõnurist kirjutab:

Külapillimeeste ansamblitesse ehk külakapellidesse ühendati kõik olemasolevad muusikariistad ja esialgu võib näida, et mingisugust süsteemi polnudki (Tõnurist 1996: 72).

Tegelikult ei olnud asi nii lihtne. Külakapelli ülesanne oli eelkõige mängida tantsumuusikat pulmades, küla pidudel ja talgutel. Seega teenindas külakapell suhteliselt kitsast ringkonda: oma küla, harvem mitut küla või valda. Nagu I. Tõnurist samas rõhutab, oli eelmise sajandi algul juba märgata selget musitseerimisvormide jagunemist maaelanikkonna eri sotsiaalsete kihtide vahel: küla tantsupeol musitseeriti hoopis teistmoodi kui alevi tantsupeol. Sellest tingituna toimus ka teatav külakapellide jagunemine - osa järgis senist, kohalikke traditsioone arvestavat stiili, teiste puhul toimus sageli teatav kahestumine: külapeol mängiti endistviisi rahvalikku repertuaari, alevis aga uuemat, välismaist päritolu tantsumuusikat nootide järgi (Tõnurist 1996: 7172). Mõlemal juhul sõltus kapell kohapeal olemasolevatest pillimeestest. Eeltoodust lähtuvalt ongi meie külakapellide koosseis ettearvamatult mitmekesine, mis paneb järgnevale arengule selge pitseri.

Nagu eespool mainitud, jõudsid uudsed moetantsud ja koos nendega ka džässmuusika Eestimaale 20. sajandi teisel kümnendil, kõigepealt suuremate linnade tantsusaalidesse, 1920. aastate lõpuks aga juba ka väiksematesse kohtadesse. ${ }^{15}$ Uue suunaga üritasid kaasa minna ka erksamad külakapellid, kellest mõned võtsid asja nii tõsiselt, et nimetasid endid tõsimeeli jazzbandiks. Nii tekkis Lõuna-Eestisse (erandina ka Saaremaal Pöide-Uuemõisasse) mitmeid äärmiselt omapärase koosseisuga end džässbändina identifitseerinud ja sellest tulenevalt ka nähtavasti džässilikku tantsumuusikat mängida üritavaid ansambleid. Suundumuste järgi saab neid jagada kaheks rühmaks. Esimese moodustavad ansamblid, mis võtsid selge suuna džässile (Tali Põllumeeste Seltsi jazzorkerster, Uue-Kariste jazzorkester UK), hankides vajalikud pillid ja asudes aktiivselt kujundama repertuaari vastavas suunas, kas uusi moodsaid lugusid raadiost maha kirjutades (Tali orkester) või noodikauplustest trükitud välismaiseid seadeid ostes/tellides (Uue-Kariste jazzorkester UK). Teise rühma kuuluksid aga külakapellid, kes üritasid mängida džässilikku muusikat olemasoleva koosseisuga. Vaadelgem neid mõlemaid veidi lähemalt. 


\section{Rahvamuusika sugemetega džäss}

Kõige tüüpilisema ümberkujunemisprotsessi näiteks sobib hästi Tali külakapell ja selle baasil tekkinud Tali Põllumeeste Seltsi jazzorkester (vt foto 1). Tali vallas ${ }^{16}$ tegutses 1930. aastate algul kohaliku taluniku Karl Talu juhtimisel külakapell, kus Karl Talu ise mängis viiulit, tema vend Kristjan trumme, Arnold Ilov bandžot ja noor Hendrik Juurikas ${ }^{17}$ (alustas kapellis juba 9-aastaselt!) mandoliini (Ojakäär 2000: 207). Kapelli ümberkujunemise eestvedajaks saigi nooruke Hendrik, kes Olustveres (kus vanem vend Karl õppis põllutöökoolis) venda külastades kuulis Viljandi džässorkestrit, ${ }^{18}$ mille saksofonide corust $^{\mathbf{1 9}}$ pidas H. Juurikas veel 68 aastat hiljemgi antud intervjuus (Jõgi 2003: 9) peamiseks põhjuseks, miks temast sai saksofonimängija. Tekkinud idée fixe’i mõjul ostis H. Juurikas 1935. aastal endale jalgrattaostuks määratud raha eest pruugitud tenorsaksofoni (millest tulnud kodus tõsine pahandus) ja asus selle mängimist õppima. Mõningad algteadmised olevat ta hankinud ühelt sugulaselt, kes oskas veidi klarnetit, põhiline õppimine toimunud paratamatult omal käel, sest elati ju suurematest keskustest suhteliselt kaugel (ibid). Nähtavasti edenes asi hästi, sest järgmisel aastal ostis ka vanem vend Karl (samuti jalgratta arvelt) endale altsaksofoni ja kuna kohalik kaupmees Voldemar Kaiküll oskas mängida trompetit, oligi džässbändi kolmehäälne "edurivi” olemas. Orkestriga liitus ka akordionist Paul Tamm, ülejäänud osa bändist - viiul, bandžo

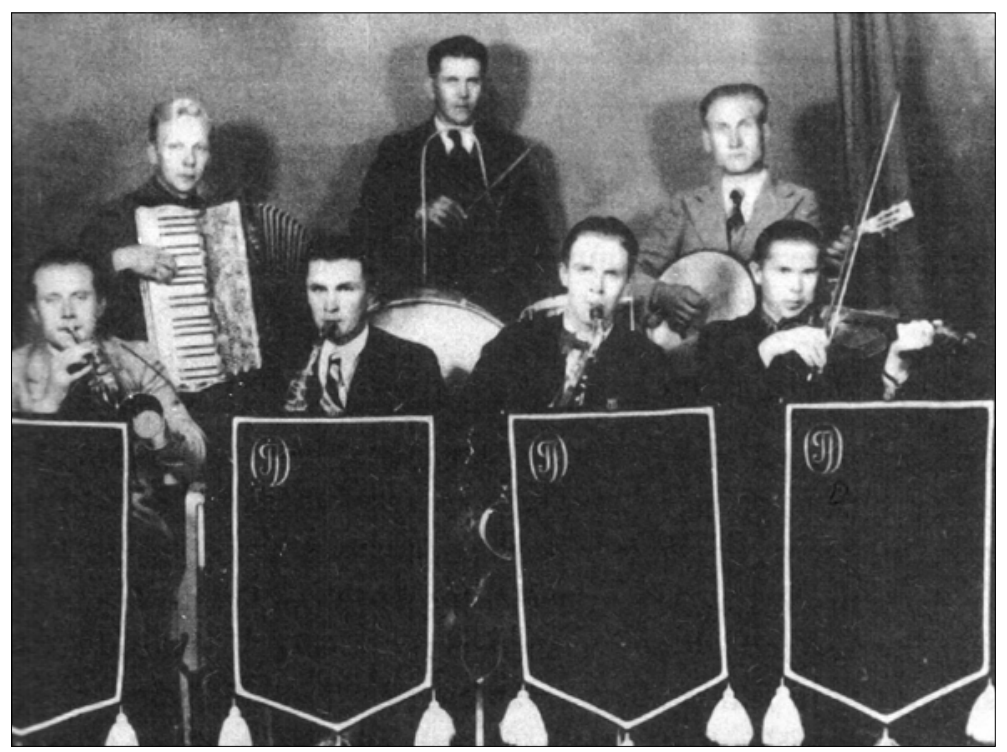

Foto 1. Tali Põllumeeste Seltsi jazzorkester 1930. aastate teisel poolel. Ees vasakult: Voldemar Kaiküll, Karl Juurikas, Hendrik Juurikas ja Karl Talu, taga Paul Tamm, Kristjan Talu, Arnold Ilov. H. Juurika kogust. 
ja trummid tulid eelnevalt tegutsenud Karl Talu külakapellist. K. Talu jäi esialgu ka orkestri juhiks edasi. Repertuaarivärskendamise eest hoolitsesid põhiliselt vennad Juurikad - igal nädalavahetusel istuti raadio juures ja kuulati Tallinna parimate orkestrite esinemisi, ${ }^{20}$ Karl kirjutas üles sõnad ja Hendrik viisid. ${ }^{21}$ Siit pärinevad ka H. Juurika esimesed seadete tegemise kogemused (Jõgi 2003: 11).

Nagu H. Juurikas samas meenutab, kuulasid nad 1936. aastal raadiost ka Priit Veebeli esimese džässikontserdi ülekannet Estonia kontserdisaalist, mis jättis neile väga ereda mulje. Hiljem hakati Esto-Muusika Kilingi-Nõmme poest hankima ka Saksamaa suurima filmitootja UFA (Universum Film AG) filmimuusika noote. Nagu H. Juurikas meenutab, sai Tali orkester üsnagi tuntuks ja nende tööpiirkond ulatus Häädemeestest Karksi-Nuiani. Erilise uhkusega mainib ta, et Vabadussõja mälestusmärgi avamisele Karksi-Nuias 23. juunil 1936. aastal kutsuti mängima just neid, mitte Pärnu või Viljandi orkestrit. Tali jäzzbänd mängis seal 11 lugu (kava pole teada) ja tasu oli rikkalik - 20 krooni mehe kohta, mille eest sai sel ajal 3 paari korralikke kingi või keskmise ülikonna (Jõgi 2003: 12).

Teiseks teadlikult džässiliku suuna valinud külaorkestriks oli Viljandist vaid paarikümne kilomeetri kaugusel asuvas väikeses Uue-Karistes aastatel 19381940 tegutsenud tantsuorkester UK, mis esines nii kodukohas kui ka ümbruskonnas (Hallistes, Rimmus, Vana-Karistes, Kõpus jm). Lisaks tantsumuusika

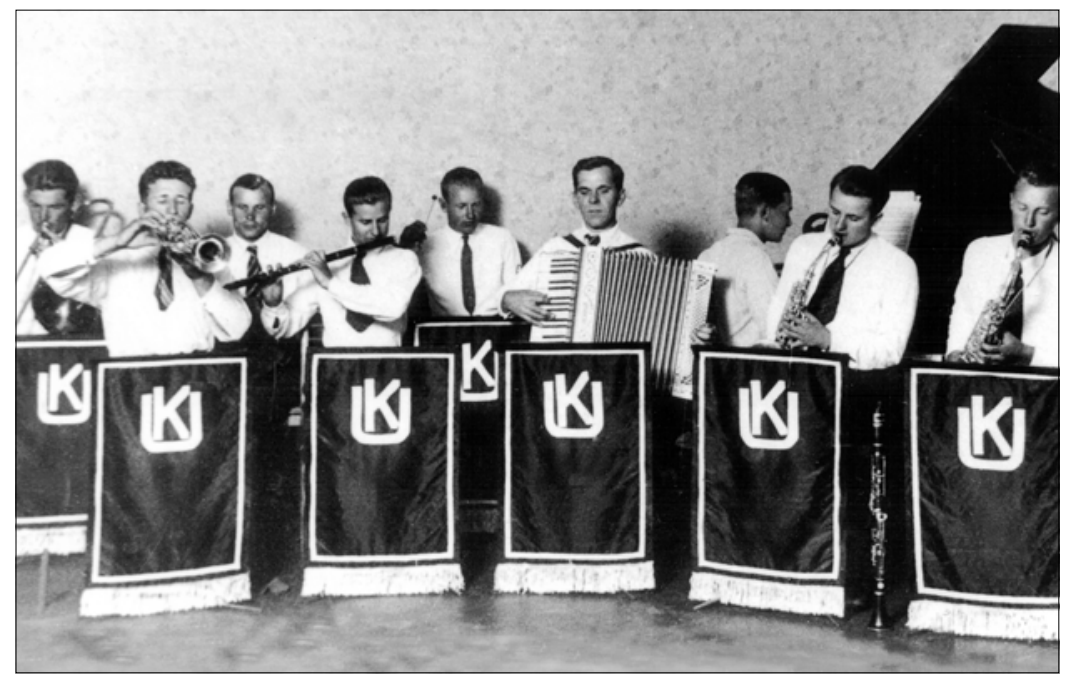

Foto 2. Uue-Kariste jazzorkester UK 1938. aastal. Vasakult: Jaan Parts, Elmar Põder, Adolf (Ats) Laanmets, Eino Juttus, Martin Viik, Karl Piiskop, Hillar Ruuber, Ervin Juttus ja Paul Juttus. E. Juttuse kogust. 
mängimisele anti Eino Juttuse andmeil ka kontserte. Orkestri asutasid kolm venda, Ervin, Paul ja Eino Juttus, sinna kuulus 9 pillimeest ja 1938. aastal tehtud fotol (vt foto 2) on nad koosseisus alt- ja tenorsaksofon, flööt, trompet, tromboon, akordion, bandžo, klaver ja trummid. Orkestri juhiks oli vendadest vanim - Ervin Juttus. Tüüpilisest külakapellist erines see koosseis ka oma mängijate suhteliselt hea muusikalise tausta tõttu - nad kõik olid saanud muusikalist algõpetust silmapaistva pedagoogi ja orkestrijuhi Enn Kiilaspea ${ }^{22}$ käest.

Tundub siiski, et kõnesoleva orkestri koostamisel on kehtinud sama printsiip kui külakapellide puhul - kedagi ei jäeta kõrvale -, sest selline koosseis oli selgelt ebapraktiline. Kuna flööt ei olnud tüüpiline tantsuorkestri pill, ei olnud neil võimalik ilma ümbertegemata kasutada ühtki trükitud nooti. Viie puhkpilliga koosseis ei saa siiski enam ilma seadeteta mängida ja nagu selgub Eino Juttuse kirjast siinkirjutajale, hangiti põhiosa repertuaarist Esto-Muusika kohaliku äri kaudu, ${ }^{23}$ osa lugusid, mida poest ei saanud osta, nt popurriid moesolevaist lauludest, seadis orkestri juht Ervin Juttus ise.

Kahjuks pole nende tegevuse ja taseme kohta mingeid andmeid ei ajakirjanduses ega teiste muusikute mälestustes säilinud, helijälgedest rääkimata, ja seetõttu on raske nende taseme üle objektiivselt otsustada.

Seega toimis toodud orkestrite puhul Murdocki teooria kohaselt integratsioon - kõik uue kultuurinähtuse põhitõed võeti omaks ja püüti end nendega võimaluse piires samastada.

\section{Džässi sugemetega rahva(lik)muusika}

Teine rühm tundub akulturatsiooni jälgimise seisukohast huvipakkuvamgi, sest selle vahendusel on paremini jälgitav protsessi algstaadium. Siia jaotusse kuuluvaid külakapelle on praeguseks hetkeks teada kolm:

* Kaarli Sammaste Jazz - 3 viiulit, kitarr, bandžo, balalaika ja trummid;

* Karutsi Jazz - 2 viiulit, lõõtspill, kitarr, 2 bandžot, tšello, kontrabass ja trummid;

* Pöide-Uuemõisa Jazzorkester - viiul, klarnet, lõõtspill, 2 kitarri, 2 trummimeest, kannel ja 4 mandoliini;

Kõik kolm on tolle aja džässorkestri jaoks äärmiselt ebatüüpilised - kannelt, mandoliini või balalaikat ei kasutatud toona üheski tavalises džässbändis, samas puudusid neis aga saksofon või mõni muu puhkpill. ${ }^{24}$ Kuigi neil kõigil oli koosseisus trumm (Pöides koguni kaks), ei olnud need päris džässbändis kasutatavad trummid, vaid puhkpilliorkestrist laenatud inventar, mis oli käepäraste vahenditega kohandatud kasutatavaks. ${ }^{25} \mathrm{Ka}$ lõõtspill ei ole tavaline džäss- 
ansambli pill - olles küll akordioni sugulane (mis tol ajal ülipopulaarsena oli kasutusel enamikus tantsuorkestritest), seab ta oma konstruktsiooni omapära tõttu mägijaile ranged helistikulised piirid, mis on eriti ebamugavad puhkpillimängijaile (v.a in $C$ pillid).

Neil omapärastel koosseisudel võib leida peale eelmainitud (külakapellidesse ühendati kõik olemasolevad muusikariistad) põhjuse ka teise loogilise põhjenduse: väikesed keelpillid nagu mandoliin ja bandžo on ka suhteliselt nõrga kõlajõuga, nende kuuldavaks tegemiseks oli seega ainult üks võimalus - neid tuli dubleerida. Ka kaks trummimeest Uuemõisa orkestris on seletatav objektiivse põhjusega - nagu fotolt näha (vt foto 7), polnud neil džässbändile vajalikku jalapedaaliga trummikomplekti, seega ei saanud üks mees mängida samaaegselt nii väikest kui ka suurt trummi.

Kõigist kolmest toodud ansamblist on kahjuks väga vähe andmeid, kõige vähem Kaarli Sammaste bändist. Ainus jälg viimasest on Viljandi Muuseumis olev foto (vt foto 3), mis tõestab, et 1930. aastal nad juba tegutsesid; fotol olevate meeste nimed ei ole teada. ${ }^{26}$ Nagu fotolt selgub, on see puhtakujuline keelpilliansambel, mida on täiendatud algelise, kuid juba selgelt tantsuorkestrile määratud trummikomplektiga, samas pole aga koosseisus ühtki bassipilli. Kuid nagu kirjutab I. Tõnurist:

Vanade külakapellide koosseisude ja ka mängukirjeldustega tutvumisel tekib siiski kahtlus, kas bassipill üldse nõutav ansamblipill oligi (Tõnurist 1996: 81).

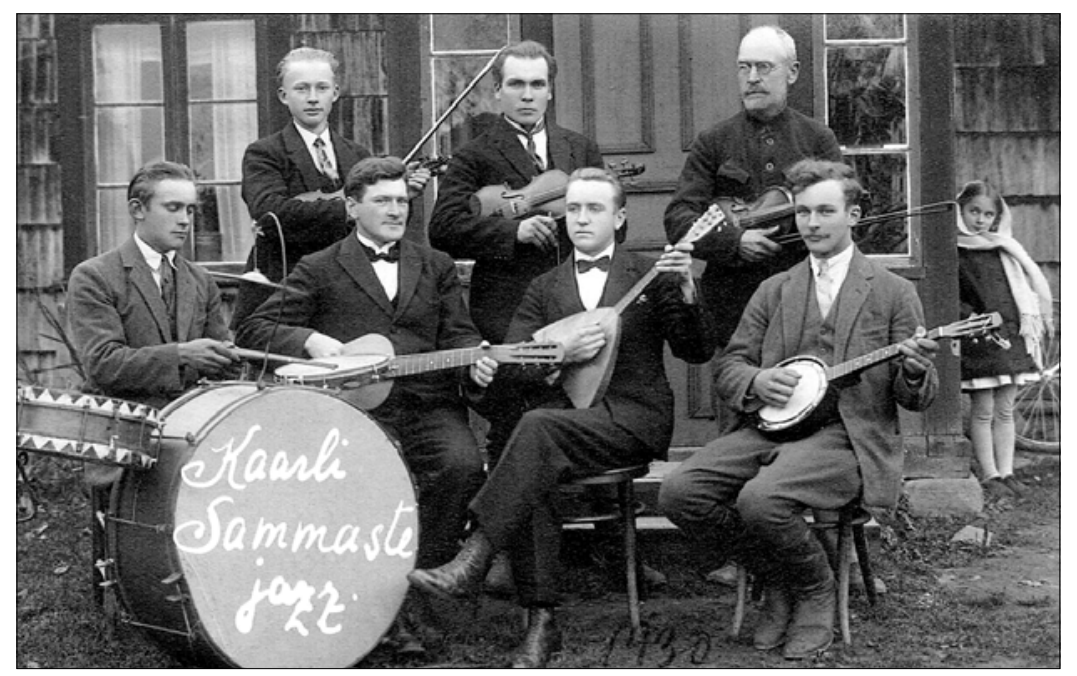

Foto 3. Kaarli Sammaste jazz 1930. a. VM $10606^{27}$. 
Seega on üsnagi tõenäoline, et seegi ansambel oli juba varem eksisteerinud külakapellina ja nüüd võtnud lihtsalt kaasaegsema suuna. Sammaste ei asu Uue-Karistest kaugel ja nii oli naabervallas elanud Eino Juttus, kes mõned aastad hiljem mängis Uue-Kariste džässbändis, nende eksistentsist küll teadlik, kuid et ta oli siis peolkäimiseks veel liiga noor, pole ta neid mängimas kuulnud (telefoniintervjuu autorile 26. 06. 2007). Tema väitel oligi see rohkem lokaalse tähtsusega ansambel, kes oma vallast kaugemal esinemas ei käinud ja Uue-Kariste orkestri tekkimise ajal nad enam ei tegutsenud. Siinjuures on aga omaette näitajaks fakt, et juba 1930. aastal tunti ka väikestes maakohtades huvi džässmuusika vastu.

Veidi rohkem andmeid õnnestus leida Karksi vallas Karutsis tegutsenud Karutsi Jazzi nimelise külakapelli kohta. Seda nähtust ahvatles lähemalt uurima üks Postimehe artikkel ("Vana kultuuritegelase juubel”, PM 1943, 13. 03), milles räägitakse Karksi valla taluperemehest Jaak Karust, kes osaleb kohaliku Laulu- ja Muusikaseltsi tegevuses juba paarkümmend aastat ja, olles kaasa läinud moodsa ajaga, mängib nüüd koos oma nelja pojaga kohalikus jazzorkestris. Kuigi artiklis on juttu 1943. aastast, selgus uurimise käigus, et andmeid Karutsi Jazzi olemasolust on juba 1920. aastate lõpust ja 1930. aastate algusest (sõja-aega jäi vaid järellainetus). Loogiline oli arvata, et orkestri koosseis oli mõnevõrra suurem, sest on ebatõenäoline, et kogu muusikaselts oli vaid üks pere!

Eeltoodud andmeid õnnestus mõningal määral täpsustada Jaak Karu ${ }^{28}$ sugulase ja Karksi koduloouurija Helve Joone ${ }^{29}$ abiga, kelle erakogus leidus ka kaks fotot nimetatud orkestrist (vt fotod 4 ja 5). H. Joon kirjutab:

1920.-date aastate lõpul või 1930. a. algul (täpset aega pole teada) asutas J. Karu perekonnaorkestri, kus mängisid tema pojad Hans (viiul), Juhan (banso) ja Hendrik (kitarr), Jaak Israel (hilisem J. Karu väimees) ja paar meest naabertaludest. ${ }^{\mathbf{3 0}}$ Pereisa Jaak mängis ise viiulit ja õpetas nooti ning viiulimängu oma poeg Hans Karule ja väimees Jaak Israelile. [---] Mängiti Sudiste külas, looduslikult kaunis kohas Kõdara mäel, kus korraldati maituld, jaanipäevi, eeskavaga seltsipidusid [---] tantsuks mängis "Karutsi jäts”. [---] Jäts oli hinnatud tantsuorkester kogu ümbruskonnas: Nuias (praegu Karksi-Nuia), Taageperas, Abjas, Penujas, Ärikülas, Sinejärvel, Viljandis ja mujalgi (kiri autorile 13. 03. 2007).

Siit saame teada ka orkestri nime Karutsi Jazz, mis rahva seas kõlas Karutsi Jäts. Huvitava faktina selgub, et trummidel, kus tavaliselt on bändi nimi, oli neil logona naeratav mehenägu koos tekstiga The Melodies Boys ${ }^{\mathbf{3 1}}$ (vt foto 5), kuigi H. Joone andmeil neid selle nime all ei tuntud. 


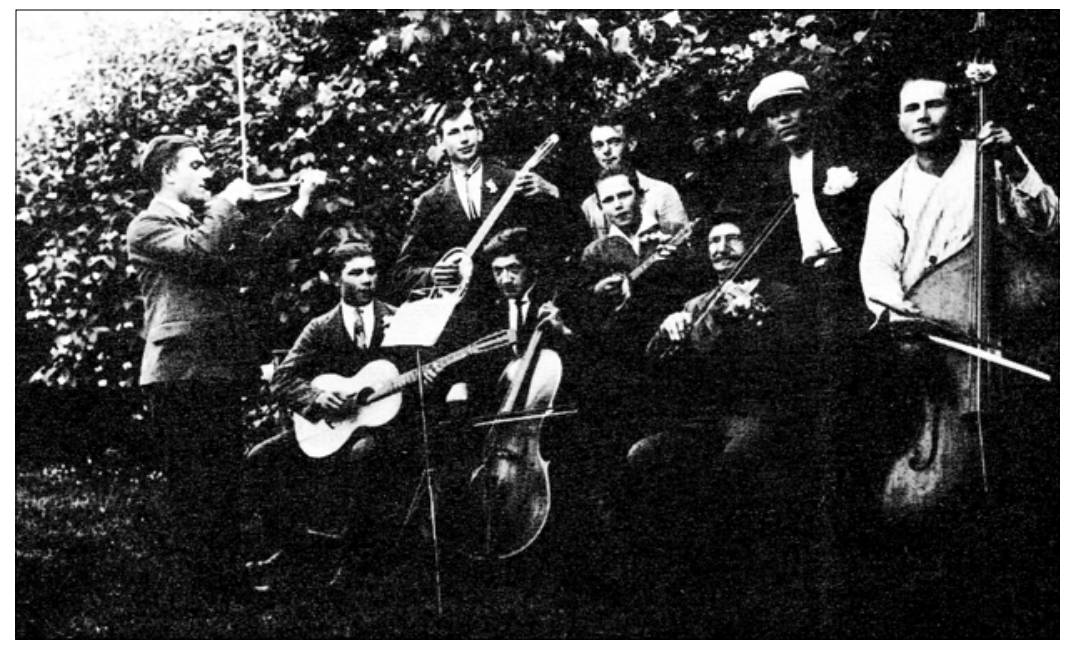

Foto 4. Karutsi Jäts. Vasakult: Hans Karu, Hendrik Karu, Jaak Israel, Ernst Vene, Juhan Karu, Jaak Karu ja Juhan Kadak. Muusikute taga seisavad kaks orkestrisse mittekuulunud naabrimeest. H. Joone kogust.

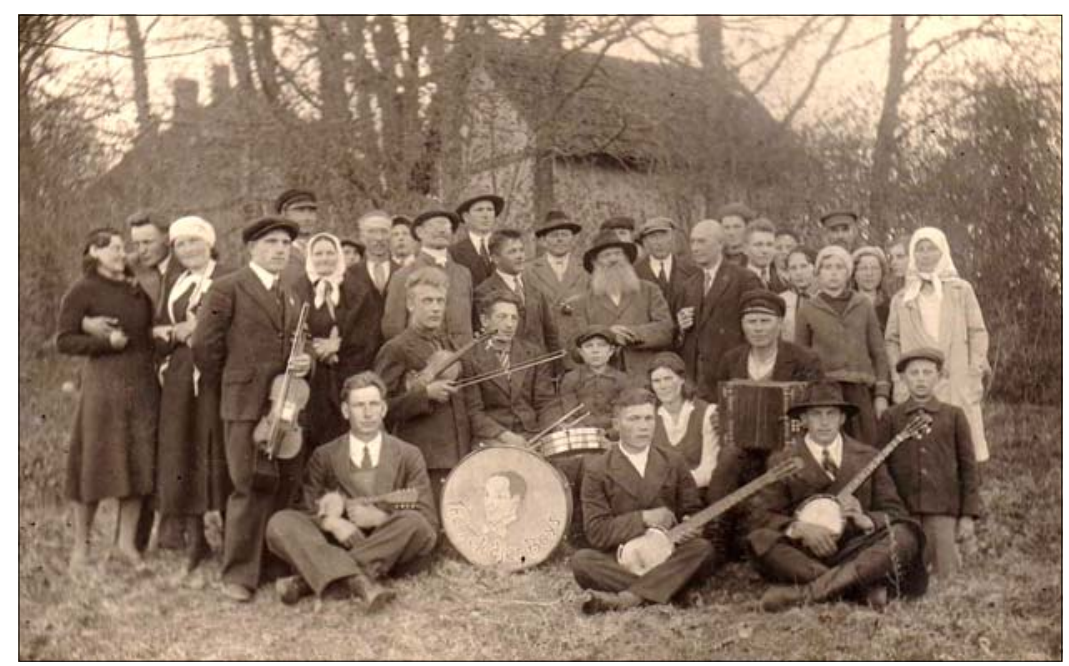

Foto 5. Karutsi Jäts naabritalu simmanil: vasakult viiuliga Hans Karu, tema ees istub Jaak Israel, viiuliga August Scherbakov (Scherbakof), ${ }^{32}$ tema taga Jaak Karu, trummar Hans Mägi, Ernst Vene ja Hendrik Karu, lõotspilliga istub Juhan Kadak, kes tavaliselt bassi mängis. H. Joone kogust. 
Fotodelt saame teada orkestri pillilise koosseisu: 2 viiulit, lõõtspill, kitarr, 2 bandžot, tšello, kontrabass ja trummid. Nagu nendel arvatavasti 1933. või 1934. aastal tehtud fotodel näha, varieerus bändi koosseis mõningal määral, mis viitab sellele, et nad ei kasutanud kuigi keerulisi mitmehäälseid seadeid, mis nõudnuks alati kogu koosseisu kohalolekut. See oli omapärane koosseis, mis ei sarnanenud ühelegi traditsioonilisele orkestritüübile, sisaldades siiski kõikidelt (peale puhkpilliorkestri) midagi ja kinnitades nii I. Tõnuristi väidet, et külakapellides ei jäeta kedagi kõrvale (Tõnurist 1996: 72). Nii Tartust, Viljandist kui ka Valgast oli võimalik tellida välismaiseid trükitud orkestratsioone ja nagu Uue-Karistegi puhul nägime, ei kujutanud jõukamale talunikule, nagu J. Karu seda Postimehe mainitud artikli andmeil oli, korralike pillide ja nootide hankimine ületamatuid probleeme. Pole andmeid, et Karutsi Jäts seda võimalust oleks kasutanud, aga ega sellisele ebatavalisele koosseisule mingeid tüüparranžeeringuid ka ühestki poest võtta oleks olnud. Nende noodikogust on H. Joone perearhiivis säilinud üks poolik noodiraamat bassipartiidega, mis meid vähe edasi aitab, sest üksnes bassi noodi järgi on raske teha järeldusi seade kohta. Lugude pealkirjade ja rütmide järgi otsustades sisaldas see vihik tüüpilist eelmise sajandi alguse tantsumuusikat - valsid, polkad, reinlendler, vengerka, padespannid, üks krakovjakk. ${ }^{33}$ Kuna noodiraamatu sisekaanele on kirjutatud "Karutoosi J. Karu Noodi-kogu nr 1", viib see mõttele, et selliseid noodiraamatuid pidi nähtavasti olema mitu, moodsamad lood omaette raamatus. ${ }^{\mathbf{3 4}}$ Seda mõttekäiku toetab loogika, et ainult sellist repertuaari mänginud külakapelli poleks keegi jazzbändiks nimetanud, see oleks kõlanud juba pilkamisena.

Kolmandana kuulub siia rühma Pöide Uuemõisa jazzorkester, mis on eeltooduist kõige omapärasema koosseisuga - viiul, klarnet, lõõtspill, 2 kitarri, 2 trummimeest, kannel ja 4 mandoliini. Kui lähtuda väitest, et nad püüdsid tõesti mängida džässi (millele viitab ju orkestri nimigi), oleks see teadaolevalt esimene katse Eestimaal, aga võimalik, et kaugemalgi, mängida džässi kandlega. Sellise koosseisu tinginud loogilistest põhjustest oli eespool juttu, kõige üllatavamalt mõjub aga tõsiasi, et Saaremaa arvatavalt esimene džässorkester tekkis väikeses asulas, samas kui Saaremaa suurimas asustatud punktis, kuurortlinnas Kuressaares, kus suviti mängisid enamasti mandrilt palgatud orkestrid, nende hulgas ka mitmed džässbändid, st oli olemas nii džässialane info kui ka eeskujud, ei ole mingeid andmeid kohaliku džässorkestri olemasolust. Saaremaa Arhiivraamatukogus on 1938. aastal tehtud foto (SMF 4022: 9) Kuressaare Eesti Seltsi orkestrist, mille koosseisu kuulusid akordion, trummid, trompet, viiul, kontrabass ja klaver (loetelu fotol olevas järjestuses), kuid andmeid muusikute nimede või orkestri mängustiili kohta seal pole. Tõenäoliselt mängis see koosseis tantsumuusikat (muidu poleks trumme vaja olnud). Kas 


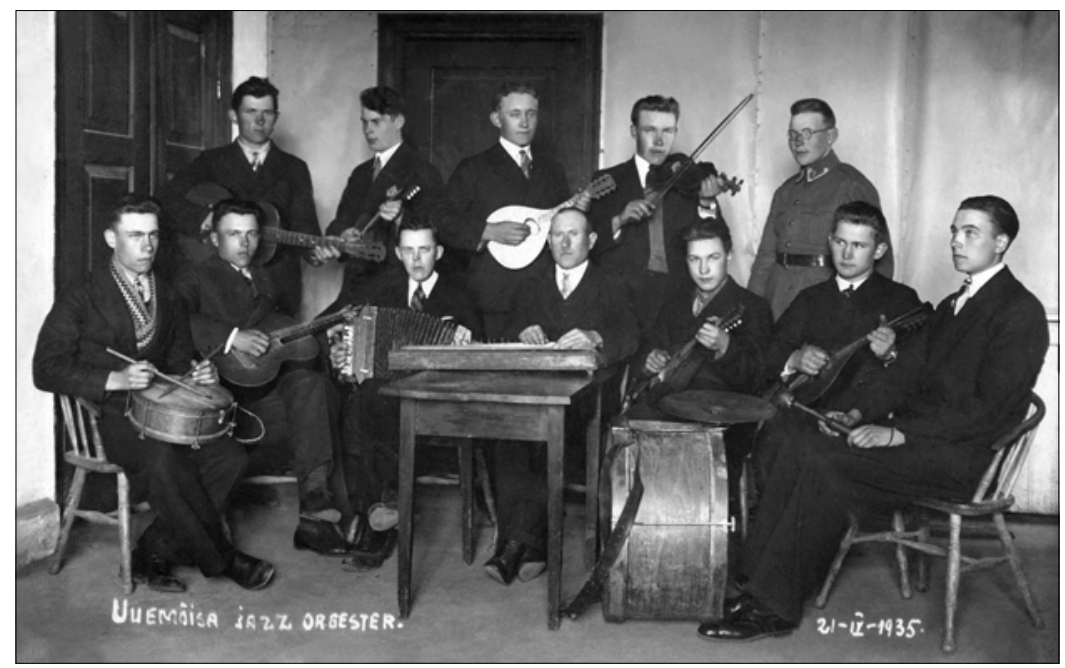

Foto 6. Pöide Uuemõisa jazzorkester (1935.a.). Ees vasakult Aleksei Koppel, Aleksander Kaldvee, Aleksander Kreek, Mihkel Peel, August Laar, Augustin Kommel ja Juhan Õun, taga Aleksander Kommel, Herman Oll, Juljus Kirsimäe, Juhan Saar, Steffan Varb. SMF 4022: 9.

nende repertuaaris oli džässilikke palu või eelistasid nad vanemat tantsumuusikat, ei ole teda. Selline koosseis pole tüüpiline kummalgi juhul, samas võimaldab see mängida muusikat mõlemas stiilis.

Konkreetseid andmeid teise rühma ansamblitest (peale Uuemõisa orkestri nimestiku) on teada vaid Karutsi Jätsi kohta ja kaasaegsete mälestuste põhjal suhtusid nemad tantsumuusikasse vägagi asjalikult, proovidega oldi tõsiselt ametis, vahepeal koguni nii tõsiselt, et talutööd tikkusid kannatama. Jaak Karu tütrepoeg Hans Israel on meenutanud:

Isa ikka rääkis, kuidas nad ööseti pillimängu õppisid ja mängimist harjutasid. Päeva pidi ju tööle minema.

Ka Aino Luukase (90) mälestused on samalaadsed:

Pillimängu kõrval kippusid talutööd lohakile jääma. Kui naabritel hein tehtud või vili lõigatud, hakati Karutsil alles sellest mõtlema (H. Joone kiri autorile 13. 03. 2007).

Kuivõrd oli kolme viimati käsitletud orkestri muusikal ühist tõelise džässiga, on raske arvata, sest pole säilinud esinemiskavu ega noote, mis võimaldaks repertuaarist lähtuvalt nende suundumuse üle otsustada. Ei ole tõenäoline, et nende seas oleks olnud improviseerivaid soliste, kuid 1930. aastate esimesel poolel polnud neid ju veel Tallinna orkestriteski. Samas, nagu väidab I. Tõnurist, oli külakapellide keelpillimängijate (eriti viiuldajate) tase üldiselt küllaltki hea 
(Tõnurist 1996: 71, 82), sageli oli ka puhkpillimängijal sõjaväeorkestri või vähemalt kohaliku pasunakoori koolitus, seega asjaliku juhi korral võis keskmiselt korralik tulemus olla täiesti võimalik.

Niisiis oli afro-ameerikalikku päritolu džässmuusika 1930. aastate keskpaigaks, pärast Eesti suuremate linnade tantsusaalide vallutamist, jõudnud juba üsnagi väikestesse maakohtadesse ja alustanud oma võidukäiku ka konservatiivsema maitsega maarahva seas. Toodud näidete varal on olemas kõik vajalikud adaptsiooni vaheastmed traditsioonilisest külakapellist džässbändini. Tuleb nõustuda P. Jalkaneni väitega, et džässi kohanemise käsitlemiseks soome-ugri rahvaste kultuuriruumis on sobivaim tema pakutud valiva akulturatsiooni käsitlus, mille kohaselt [---] vana ja uue ainese vahel tekitatakse tasakaal, mille tulemusel sünnib uus kultuuritüüp (Jalkanen 1989: 13).

Selline lähenemine sobib hästi meie teise rühma orkestrite puhul, esimese grupi orkestrite puhul sobiks ka Laade pakutud akulturatsiooni astmestik: valik-omaksvõtt ja integreerimine-ühtimine. Välja jääksid vaheastmed tasakaalustamine ja tõrjumine, kuna esimese grupi orkestrite puhul neid ei toimunud. Eelnevat tõestas värvikalt Tali külakapelli näide, kes, täiendanud oma instrumentaariumi saksofonide ja trompetiga, muutus paari aastaga juba üsnagi tüüpiliseks džässbändiks. On täiesti tõenäoline, et nii Karutsi, Sammaste kui ka Uuemõisa külakapellid oleksid läbinud mõne aja möödudes sama tee tõelise džässbändini, neil oli lihtsalt vaja rohkem kohanemisaega. Samas on tõenäoline seegi, et selliseid pool-džässbände võis olla Eestimaal rohkemgi, praegu me lihtsalt ei tea neist midagi.

Kõnesolevate kollektiivide muusikat oleks õige määratleda kas meie rahva(liku)muusika mõjutustega džässilikuks (esimene grupp) või džässilike mõjutustega rahvalikuks tantsumuusikaks (teine grupp). Kui tahta neid siiski kuidagi täpsemalt klassifitseerida, sobiks ilmselt termin külajäts, sest džässilikku tantsumuusikat mängida nad omal moel tõenäoliselt siiski üritasid.

Mõningaid paralleele võiks siin tuua Soome džässis ${ }^{\mathbf{3 5}}$ samal arenguetapil tekkinud rahvalikku džässistiili haitarijazziga, ${ }^{\mathbf{3 6}}$ mis oli tagasihoidlikuma muusikalise hariduse ja konservatiivsemate tõekspidamistega lihtrahva (harrastus)muusikute reaktsioon džässkultuuri suurlinlikule välisele särale. Kui Soomes tuli initsiatiiv kõnesoleva stiili tekkeks linnade töölisklassi hulgast, siis Eestis olid algatajaks külakapellid, kes võtsid üle neile sobiva osa uuest muusikast (uued meloodiad, huvitavad rütmid) ega kiirustanud sugugi muutma harjunud koosseise, üritades hoopis kohandada uut stiili olemasolevate võimalustega. Olulist vahet võis märgata ka leviulatuses - Soomes oli see nähtus massiline, tekitades lausa "kaksikvõimu": linnade esinduslikemates tantsusaalides/restoranides võimutses diksiländmuusika, äärelinnade ja maarahva tantsupidudel aga haitarijazz (Haavisto 2000: 112-113). Eestis mingit “seisus- 
likku" vahet täheldada ei saa, pigem oli probleem maarahva suuremas konservatiivsuses moetrendidega kaasaskäimisel. Soome oli võrreldes Eestiga ka oluliselt paremini ettevalmistatud selle uue kultuurinähtuse mõistmiseks (sellest lähemalt vt Lauk 2007: 124, 132).

\section{Kokkuvõtteks}

Tuleb tõdeda, et mingite põhjapanevate järelduste tegemiseks antud küsimuses on meie käsutuses olev info siiski liialt napp.

Rääkides külakapellidest ja nende püüdest mängida džässilikku tantsumuusikat, tekib nagu iseenesest küsimus, kas pole siin tegemist rahvusliku ehk etnilise džässi ilmingutega. Paraku ei ole meil põhjust pidada seda nähtust rahvuslikuks džässiks, sest pole andmeid, et külakapellid oleks oma džässilike tantsupalade aluseks kasutanud eesti rahvamuusikast pärit teemasid. ${ }^{37}$ Kas kõnealused ilmingud oleksid võinud viia rahvusliku džässi sünnini, on raske arvata. Teatavasti katkestasid II maailmasõda ja okupatsioonid meie kultuuri arengu omal karmil moel. Näiteks Soomes, kus sellist katkestust ei toimunud, areng igatahes rahvusliku džässi tekkeni ei viinud. Hoolimata suurest populaarsusest lihtrahva hulgas suubus haitarijazzi areng osaliselt akordionil mängitavasse džässi, osaliselt aga lihtsamasse popmuusikasse (Soome Jazz \& Pop Arkisto teaduri Juha Hendriksoni intervjuu autorile 20. 11. 2004).

Arvatavasti oli nähtus ise meie rahvakultuuri jaoks siiski liialt uus ja kauge. Kõigepealt oli vaja rohkem aega selle põhjalikumaks tundmaõppimiseks, alles seejärel tulnuks kõne alla selle kujundamine rahvuslike traditsioonide vaimus. Mõtted selles suunas siiski liikusid, mida näitab püüd luua uusi rahvusliku taustaga seltskonnatantse ${ }^{38}$ (oli ju džäss 1930. aastate algul siiski põhiliselt tantsumuusika) ja uute seadete abil kaasajastada juba tuntud tantse (jooksupolka, viru valss jt), ${ }^{39}$ st kiirendada ja suunata adaptatsiooniprotsessi. Siin leiab veel kord kinnitust ka Wolfgang Laade väide, et akulturatsiooniprotsess vajab piisavalt aega. Ja kuigi mõningaid vihjeid selle protsessi võimalikule käivitumisele võib külajätsi tekkimises leida, oli aega siiski liialt vähe olnud ja tõsiseltvõetavamalt saab rahvusliku džässi tekkest rääkida alles paarkümmend aastat hiljem seoses Uno Naissoo loominguga.

Aeg on näidanud, et tol ajal ilmselt üsnagi ketserlikuna tundunud idee püüda ühendada rahvamuusika väljendusvahendeid džässi põhimõtetega, ei ole seda sugugi. Viimasel ajal on üha sagedamini hakatud rääkima hoopis sellest, kas ei peaks ka džässi käsitlema koos rahvamuusikaga, kuna tema tekkimisel ja arengul on sellega palju sarnast. ${ }^{40}$ 


\section{Kommentaarid}

1 Joachim-Ernst Berendt (1922-2000), üks tunnustatuimaid džässiajaloo uurijaid. Tema Jazziraamat (Das Jazzbuch 1989; eesti keeles 1999) on üks väheseid tervet džässi ajalugu hõlmavaid käsitlusi.

2 Ameerika neegriorkestritelt on pärit tava anda muusikuile hüüdnimed, mis siis koos nimega (jutumärkides või ka ilma) välja kirjutatakse. Nii on neegermuusikute seas arvukalt kuningaid, krahve, hertsogeid (ingl king, count, duke). Mõnel puhul on mehed saanud hüüdnime all nii tuntuks, et on selle endale artistinimeks võtnud ja sageli õiget eesnime enam ei kasutatagi, nt Count Basie, Duke Ellington.

Edward Kennedy Duke Ellington (1899-1974) helilooja, orkestrijuht ja pianist, üks džässi arengut enim mõjutanud muusikuid. Tema tähtsus džässi ajaloos helilooja, orkestrijuhina ja novaatorina on hindamatu, panus pianistina jäi tagasihoidlikuks.

${ }^{3}$ Svingimine on üks neist nähtustest, mis on siiamaani üheselt defineerimata, hoolimata sellest, et kõik džässmuusikud teavad, mis see on. Rahvusvaheliselt tuntud vene džässpianist ja -teoreetik Igor Bril on selle nähtuse sõnastanud järgmiselt: Sving - see on rütmiline impulsiivsus, mis tekib esitamise momendil ja tekitab džässimprovisatsioonis pinge (Bril 1982: 46). Sving on džässi olulisimaid rütmikomponente, tänu millele džäss saavutab samasuguse pinge nagu süvamuusika tänu oma vormistruktuuri(de)le. Svingi kõige iseloomulikumaid tunnuseid on kahe kaheksandiknoodi ( $\square$ ) mängimine trioolina (kaks esimest nooti pidega seotult, kusjuures nooti seda ei märgita), ja nn laiskade sünkoopide rohkus. Kuigi sving on kõige otsesemalt seotud aafrikaliku rütmikaga, tekkis ta alles siis, kui aafrikalikku rütmitunnetust rakendati koos euroopalike meetrumitega (Berendt 1999: 198).

4 Paul Whiteman (1890-1967), 1920. aastate kuulsaimaid džässorkestri juhte, esimesi hea muusikalise haridusega pillimehi džässmuusikute ridades, esimene arranžeerija džässorkestri juhtide seas. Alustas muusikaõpinguid 7-aastaselt ja juba kümme aastat hiljem oli Denveri sümfooniaorkestri aldirühma liider. Džässiga puutus kokku esmakordselt 1911. aastal San Franciscos (Whiteman 1926: 33). Kuulsus saabus 1920. aastal, kui tema orkestri plaadistatud Schonbergeri "Whisperingi" müüdi 1,8 miljonit plaati; 1920 . aastast New Yorgis. Tema ideeks oli algusest peale luua "sümfooniline džäss" (McCarty 1971: 20).

5 Erandiks on siin džässi sünnimaa USA, kus eksisteerivad kõrvuti paljude rahvaste kultuurid ja uue kultuuriilmingu ilmumisajal ei olnud (ega ole siiani) ühtset rahvuskultuuri välja kujunenud. Tõenäoliselt seda ei juhtugi, sest USA ei ole rahvusriik nagu Eesti, Soome või Läti.

6 E. Ansermet avaldas 1919. aastal esimese arvestatava artikli džässmuusikast, R. Goffin esimese džässiraamatu (Kernfeldt 2002 II: 50).

7 Minikassett "Jazz-muusika algataja Eestis, Kurt Strobeli elulugu", sisse loetud 8. aprillil 1979. aastal (Strobeli 75. sünnipäeval) Warradale'is Austraalias. Originaal V. Ojakääru valduses. Sama teemat käsitleb ka S. Frederick Starr raamatus Red \& Hot. The Fate of Jazz in the Soviet Union, 1917-1980 (Starr 1983: 42-43).

8 Eri Klasi isa.

9 Asus Tallinnas Raekoja platsil. Praegu on neis ruumes restoran Maikrahv. 
${ }^{10} \mathrm{~K}$. Paalse ühines orkestriga sügisel, suvel oli ta sundaega teenimas Tartu Ratsarügemendis.

${ }^{11}$ V. Compe nime on kirjutatud nii Compe kui ka Kompe, Poolas, kuhu ta 1937. aastal elama asus, kasutati koguni nimekuju Comp-Kompe. Tema tütar peab õigeks siiski Compe.

12 1938. aastal toimunud Kohtla-Järve kaevanduse I laulupäeva bukletis (lk 14) rahvapeo kava lõpus on teade, et tantsuks mängib Kukruse jazzband. Bändi koosseisu, juhi ega repertuaari kohta pole bukletis aga sõnagi. (Siinkohal tahaksin tänada staažikat koorijuhti ja muusikapedagoogi Iris Reimetsa, tänu kellele õnnestus selle bukletiga tutvuda.)

${ }^{13}$ Nagu kirjutab Rahvaleht, õpetas tuntud tantsuõpetaja Sergei Insarov koos oma abiliste Tamara Istomina ja Viktor Reiteliga Narvas, Pärnus, Rakveres, Paides ja maakohtadeski viie aastaga tantsima umbes 12000 inimest (RL 1926: 9. märts).

14 Jaak Allmere räägib Treffneri Gümnaasiumi poiste orkestri üsna laiast esinemisgeograafiast Paides, Järva-Jaanis, Rakveres (Ojakäär 2003: 150). Filmiarhiivis on foto Paide uusaastaballilt, kus laval on Viljandi Melody Makers (EFA 3-7178) jne. J. Allmere (sünd 1912) lõpetas 1931. aastal Treffneri Gümnaasiumi, kus tema muusikaõpetajaks oli Adalbert Wirkhaus. Allmere muusikahariduse kohta andmed puuduvad, küll on teada, et gümnaasiumipäevil pani A. Wirkhaus ta kooli sümfooniaorkestrit juhatama (Ojakäär 2000: 211).

J. Allmere asutas ja juhatas mitmeid (salongi)orkestreid Elvas, Rakveres, Pärnus. Kõige džässilikum neist oli Pärnu Rannakohviku orkester 1943. aastal. 1944. aastal emigreerus J. Allmere Rootsi, kus algul mängis paljudes restoraniorkestrites, hiljem oli mitmete sümfooniaorkestrite viiuldaja, kunstiline juht ja dirigent; tegutses pikka aega ka pedagoogina Örnsköldsviki muusikakoolis. 1987. aastal asutas sümfoniettorkestri Prima Vista, millega ta 1992. aastal ka Eestis esinemas käis (Ojakäär 2003: 225).

${ }^{15}$ Valgast pärit kirjanik Valve Saretok kirjeldab oma noorusmälestuste ainelises romaanis Läbi uduliniku üsna põhjalikult Valga noorsoo tegemisi ja huvisid eelmise sajandi teise veerandi hakul (Saretok 1957: 115). V. Saretoki andmeil puhkes Valgas moodsate tantsude buum 1920. aastate algupoolel, seega mitte oluliselt hiljem kui Tallinnas.

${ }^{16}$ Tali (ka Talli) asula oli Eesti Entsüklopeedia (EE 1936: 1363) andmetel samanimelise, umbes 1400 elanikuga valla keskus Edela-Eestis Saarde kihelkonnas (vt joonis 1).

${ }^{17}$ Hendrik Juurikas (1921-2004) on tähelepanuväärne isik Eesti muusikas, olles üle 50 aasta Võru muusikaelus kesksel kohal nii saksofonisti-klarnetisti, orkestrijuhi, pedagoogi kui muusikakooli direktorina. Tema talupidajast isa Jaan, kelle UueJärve talu asus samas Tali vallas, oli tsaariarmees mänginud puhkpilliorkestris kornetit, lisaks sellele oskas ta ka viiulit (VK 1995, 5: 4). Emapoolse vanaisa Adam Kosenkraniuse juures tegi 4-aastane Hendrik varakult tutvust ka grammofoniga ja selle vahendusel süvamuusikaga. Hendrik on ka Juurikate muusikutedünastia esiisa - tema poeg Tiit Juurikas on tunnustatud levimuusika pianist-arranžeerija ja pojapoeg Raun, kes õpib Eesti Muusika- ja Teatriakadeemias, on endale juba nime teinud džässpianistina, pojatütar Age aga süvamuusika pianistina.

18 Viljandis oli siis juba kaks korralikku džässilikku tantsumuusikat mängivat orkestrit - Melody Makers ja Akkord. Kumba neist H. Juurikas kuulis, pole teada. 
${ }^{19}$ Formaal-struktuurne ühik džässis, vastab ühele vormi täispikkusele.

20 Tunnustatud eesti džässpianisti, Eesti džässiajaloo ühe esimese uurija ja olulisema talletaja, Aadu Mutsu (1913-1993) andmeil esines The Murphy Band ringhäälingus juba 1928. aastal. Lisaks Estonia valgele saalile tehti tantsumuusikaülekandeid Dancing Palace Gloriast (K. Strobeli orkester) ja Dancing Parisist (J. Pori orkester), stuudiost mängisid Merry Pipers, Dancing Travellers, Kuldne 7, kvartett Speek-Veebel-Elts-Kruus ja Six Swingers (Mutsu 1991, nr 7: 37). Eelloetletud orkestrite regulaarset kuulamist mainib lisaks H. Juurikale ka Uue-Kariste džässorkestrisse kuulunud Eino Juttus (intervjuu autorile 3. jaanuaril 2007).

${ }^{21}$ See fakt, et kuuldud lugusid suutis mälu järgi transkribeerida ilma muusikalise hariduseta 15- aastane külapoiss, tundub lausa uskumatu. Kuid nagu H. Juurikas samas intervjuus mainib, oli Tali 6-klassilises koolis väga tugev muusikaõpetus kirjutati viiuli järgi diktaati(!). H. Juurika muusikalise alghariduse juures tuleks nähtavasti arvestada ka tema isa osa - tsaariarmee orkestrandina pidi ta noodikirja korralikult valdama ja kuigi intervjuus seda ei mainita, võib arvata, et koos oma lastele pillimängu õpetamisega tegi isa neile juba kodus selgeks ka noodikirja saladused.

${ }^{22}$ Möödunud sajandi esimesel poolel Viljandi- ja Pärnumaal tegutsenud koolmeister ja orketrijuht Enn Kiilaspea (1872-1943, Ants Kiilaspea isa, Tiina ja Enn Kiilaspea vanaisa), kes olevat pööranud erilist tähelepanu sümfoniettorkestrite (maal nimetati neid segaorkestriteks) loomisele. Olles Fr. Saebelmanni õpilasena ise hea viiulimängija, aga osates mängida ka puhkpille, õpetas ta sageli kõik pillimehed ise välja. Tema parimaks orkestriks peetakse Halliste 20 liikmelist segaorkestrit, kes olevat esitanud üsna nõudlikku repertuaari: F. Suppé "Luuletaja ja talupoeg", parafraas V. Bellini "Normast", C. P. E. Bachi "Kevade ärkamine”, J. Straussi "Ilusal sinisel Doonaul", "Viini veri" jt. Omapärana on mainitud, et Kiilaspea orkestrites ei kasutatud kunagi löökpille, sest need segavad puhast muusikat (Teder 1984: 31-34). Uue-Kariste vallas oli Enn Kiilaspea viimane töökoht enne pensionile siirdumist ja suurem osa tulevase UK džässorkestri liikmetest omandasid muusikuoskused temalt ja mängisid tema õpilastena ka kohalikus segaorkestris. Poisid hankisid maestro teadmata puuduvad pillid (saksofonid ja trummid) ja hakkasid koolimajas suure õhinaga proovi tegema. Seda esimest proovi juhtus kuulma ka E. Kiilaspea, kelle kommentaar olevat kõlanud: Olite mul koolis nutikad poisid, ei tea, mis teil nü̈̈d sisse on läinud (ibid). See oli siiski esimene katsetus, ja kui arvestada sümfoniettorkestri mängijate suhteliselt head koolitust, võib arvata, et edaspidised tulemused olid siiski hoopis muud.

${ }^{23}$ Ervin Juttus töötas samas Esto-Muusika äris müüjana ja siit telliti/osteti järelmaksuga ka saksofonid. Kuna trükitud seadetes, nagu juba öeldud, ei ole üldjuhul koosseisus flööti, tegi vajalikud kohandamised Ervin Juttus.

${ }^{24}$ Olemasolevail andmeil (Männa 1995: 258) oli Pöide-Uuemõisa jazzorkestri juht Herman Oll küll klarnetimängija, kuid orkestri fotol on tal käes hoopis mandoliin, seega ei tea me, kumba pilli ta bändis mängis.

${ }^{25}$ Džässbändi trummikomplekt koosneb 3-5 eri kõrgustele häälestatud trummist; suurt trummi mängitakse spetsiaalse jalapedaaliga, mis võimaldab mängida oluliselt täpsemalt ja keerukamaid rütmifiguure, kui see nuiaga puhkpilliorkestri suurel trummil võimalik oleks. Komplekti kuulub ka spetsiaalse jala küljes olev taldrik. 
${ }^{26}$ Viidates ameerika kultuurikriitik W. J. Thomas Mitchellile kirjutab Tõnis Liibek: [---] Aina enam visualiseeruvas maailmas on ka akadeemiliste distsipliinide juures omandamas üha suuremat tähtsust visuaalse info mõistmise ja analüüsimise oskus (Liibek 2006: 9). T. Liibek juhib samas tähelepanu asjaolule, et sellises kontekstis on huvipakkuvad infoallikad just amatöörfotod ja sündmusfotod.

${ }^{27}$ Jüri Tibarilt saadud fotod, mille hulka kuulub ka siintoodu, on arvel Viljandi Muuseumis (VM 10606), Kaarli Sammaste džässbändi fotol ei ole eraldi säilikunumbrit (muuseumi teaduri Heli Grosbergi kiri autorile 18. 06. 2007).

${ }^{28}$ Karksi vallas Sudiste külas asuva Karutoosi talu peremees Jaak Karu (1871-1957) õppis Karksi kihelkonnakoolis, sai sealselt köster-kooliõpetajalt Georg Rosenbergilt muusikalise alghariduse ja viiulimänguoskuse.

${ }^{29}$ H. Joon on kirjutanud kodupaiga ajaloost ka raamatu Karksi kihelkond (1995, Viljandi).

${ }^{30}$ Eelmainitud Postimehe artikkel osutub ebatäpseks - J. Karu neljast pojast mängisid pilli ainult kolm.

${ }^{31}$ Sellise logol oleva teksti idees võib ilmselt näha paralleeli Viljandi Melody Makersi nimega; ka Tallinna bändidel oli moes suurele trummile joonistada naerunägu (Jolly Pipers, Red Hot Ramblers).

${ }^{32}$ Scherbakov siirdus H. Joone andmetel hiljem Peterburi, kus temast tuli professionaalne viiuldaja (kiri autorile 21.03.2007). Neid andmeid kinnitab Jaan Saviauk, kes artiklis Leningradi eestlaste kultuurielust 1930. aastail mainib Viljandimaalt pärit Moskva Konservatooriumi haridusega August Štšerbakovi (Saviauk 1983: 97). See fakt koos teadmisega J. Karu muusikalisest haritusest annab viite muusikute oletatavale tasemele. Nende tasemest kõneleb ka fakt, et neid Viljandisse, kus oli ju mitu korralikku orkestrit, mängima kutsuti. Hiljem, nõukogude korra tingimustes jätkas ansambel uue koosseisuga J. Israeli juhtimisel Karksi külakapellina (ibid).

${ }^{33}$ Sellega seoses meenutab H. Joon:

Hendrik Karu jutust on meeles, et "Karutsi Jätsi” mängitud lood olnud väga hoogsad. Tihti jäänud tantsuruum kitsaks ja tantsijad keerutanud pillimeestele ja pillidele peale. Tantsijate eelmalehoidmiseks pannud kontramees Juhan Kadak poogna otsa terava nõela (H. Joone kiri autorile 13. 03. 2007).

${ }^{34}$ H. Joone andmetel käis Karutsi Jäts peale kohalike külapidude mängimas Nuias (praegu Karksi-Nuia), Taageperas, Abjas, Penujas, Ärikülas, Sinejärvel ja koguni Viljandis, seega võis siin olla tegemist näitega nähtusest, millele viitab I. Tõnurist: külapeol mängiti endist viisi rahvalikku repertuaari, alevis aga uuemat, välismaist päritolu tantsumuusikat (Tõnurist 1996: 71-72). Antud juhul võisid siia kategooriasse kuuluda just džässilikud tantsulood.

${ }^{35}$ Soome džässiga on Eesti džässi arengut eriti huvitav võrrelda seetõttu, et džässmuusika jõudis mõlemasse kultuuriruumi peaaegu üheaegselt, ka meie rahvakultuur on suhteliselt sarnane.

${ }^{36}$ Haitari on akordioni rahvapärane nimetus Soomes. Otsetõlkes tähendab haitari lõõtspilli või harmoonikat.

${ }^{37}$ V. Ojakääru andmetel võis esimese eesti foxi autoriks olla hoopis tuntud süvamuusikapianist Vladimir Padva (1900-1981). V. Padva (nagu Compegi) kasutas ja kutsus üles teisigi heliloojaid kasutama tantsupalades eesti rahvaviise, mis selle aja 
džässmuusikas oli ainulaadne laiemaltki kui Eestis võetuna, seega võib neid pidada üheks esimestest etnilise džässi võimaluste otsijaiks. Padva 1925. aastal kirjutatud "Chocolate Babies" olevat olnud populaarne nii Berliinis, Bergenis kui ka neegrite revüütrupi Chocolate Kiddies esituses isegi Ameerikas (Ojakäär 2000: 348351). Kahjuks ei ole see lugu mingil kujul säilinud, seega pole võimalik otsustada ei selle džässilikkuse ega rahvuslikkuse üle. Padva kirjutatud tantsumuusikapalu on aga mänginud üks selle aja Mandri-Euroopa kuulsaimaid tantsuorkestreid Dajos Béla juhatusel (ibid).

${ }^{38}$ Päevalehe teatel tutvustasid tantsuõpetajad Stella Luts ja Herbert Küttim uusloomingulist salongitantsu Eesti valss, mis oli loodud meie rahvatantsude ainetel. Muusika telliti tuntud džässpianistilt Th. Maistelt (PL 1932, 15. 10).

${ }^{39}$ Selles kontekstis tuleks mainida ka 1930. aastate teisel poolel toimunud riigi Propagandatalituse ettevõtmist tantsumuusika eestistamiseks, mille tulemusel telliti tuntud muusikutelt mitmeid eesti päritolu tantsude uusi kaasaegseid seadeid tantsuorkestritele: Adolf Vedrolt jooksupolka ja viru valsi seade, Artur Uritammelt Jämaja labajala ja John Porilt Vändra polka seade. Kõik need lood plaadistas J. Pori orkester Bellaccord-Electro firmas (Ojakäär 2000: 122).

${ }^{40}$ Refereering kuulsa kitarristi ja džässiteoreetiku Pat Metheney ettekandest IASJ (International Assocation of Schools of Jazz) nõupidamisel New Yorgis 11. 01. 2001 (IASJ NL 2001, 28: 9-12).

\section{Allikad eravalduses}

Viljandi Muuseumi teaduri Heli Grosbergi kiri autorile 18. juunil 2007.

Soome Jazz \& Pop Arkisto teaduri Juha Hendriksoni intervjuu autorile 20. 11. 2004.

Helve Joone kiri autorile 13. märtsil 2007.

Helve Joone kiri autorile 21. märtsil 2007.

Eino Juttuse kiri autorile 29. detsembril 2006.

Eino Juttuse intervjuu autorile 3. jaanuaril 2007.

Eino Juttuse telefoniintervjuu autorile 26. juunil 2007.

Minikassett "Jazz-muusika algataja Eestis, Kurt Strobeli elulugu”, sisse loetud 8. aprillil 1979. aastal Warradale'is Austraalias, Valter Ojakääru eraarhiivis.

\section{Arhiiviallikad}

EFA $=$ Eesti Filmiarhiiv

$\mathrm{SMF}=$ Saaremaa arhiivraamatukogu fotokogu

$\mathrm{VM}=$ Viljandi Muuseum 


\section{Kirjandus}

Berendt, Joahim Ernst 1999. Jazziraamat. Tallinn: Vagabund.

Bril 1982 = Бриль, Игорь. Практический курс джазовой импровизации. Москва: Советский композитор.

Bruér, Jan 1998. Varning för jazz. Svensk Jazzhistoria vol 1. Stockholm: Caprice Records \& Rikskonserter.

EE 1936 = Kleis, Richard (peatoim) \& Tarvel, Peeter \& Veski, Johannes Voldemar (toim). Eesti Entsüklopeedia 7. Tartu: Loodus, lk 1363.

Haavisto, Jukka 2000. Puuvillapelloilta kaskimaille: jatsin ja jazzi vaiheita Suomessa. Helsinki: Otava.

Hovi, Kalervo 2002. Viinasodasta kynttiläiltoihin:Tallinnan ravintolakulttuurin historia 1918-1940. Turku: Kirja-Aurora.

Jalkanen, Pekka 1989. Alaska, Bombay ja Billy Boy. Jazzkulttuurin murros Helsingissä 1920-luvulla. Suomen etnomusikologisen seuran julkaisuja. Helsinki: Suomen etnomusikologinen seura.

Joon, Helve 1995. Karksi kihelkond. Viljandi: Viljandimaa Haridusamet.

Jõgi, Ene 2003. Hendrik Juurikas - kogu elu on muusika. Tallinn: EMA [Õpetajate täienduskoolituse lõputöö].

Kenney, William Howard 1995. Context and Definition of Jazz. Gabbard, Krin (toim). Jazz among the discourses. Durham: Duke University Press, lk 100-116.

Kernfeld, Barry (toim) 2002. The New Grove Dictionary of Jazz I, II, III. New York: Macmillan Publishers Limited.

Lauk, Tiit 2007. Jazz Development in Estonia and Finland in 1920-1945. Faravid 31. Acta Societatis Historiae Finlandiae Septentrionalis. Oulu: Pohjois-Suomen Historiallinen Yhdistys, lk 123-140.

Liibek, Tõnis 2006. Ajalooline pildianalüüs: foto ajalooallikana. Kirme, Kaalu \& Kirme, Maris (koost \& toim). Kultuuriloost noorteadlase pilguga IV. Tallinn: Tallinna Ülikooli kirjastus, lk 9-22.

Luts, Eva (koostaja) 2006. Muusikute tsitaate elust, armastusest ja tööst. Tartu: Fantaasia.

McCarty, Albert, J. 1971. The Dance Band Era. The Dancing Decades from Ragtime to Swing: 1910-1950. Philadelphia: Chilton Book Company.

IASJ NL 2001. Pat Metheney of Jazz Education. IASJ Newsletter 28, lk 9-12.

Murdock, Peter 1960. How Culture Changes. Shapiro, Harry L. (toim). Man, Culture and Society. New York: Oxford University Press, lk 247-260.

Mutsu, Aadu 1991. Happy Days are Here Again. Kultuur ja Elu 5-10 [Kultuur ja Elu Raamatukogu]. 
Männa, Heinrich (koost) 1995. Saaremaa laulupeo esimene sajand 1894-1994. 1. osa: sõnumeid kooridest, koori ja orkestrijuhtidest ning laulupidudest. Kuressaare: Oma Saar. Nettl, Bruno 1964. Theory and Method in Ethnomusicology. London: The Free Press of Glencoe.

Ojakäär, Valter 2000. Vaibunud viiside kaja. Tallinn: Eesti Entsüklopeediakirjastus. Ojakäär, Valter 2003. Omad viisid võõras väes: 1940-1945. Eesti levimuusika ajaloost 2. Tallinn: Ilo.

O‘Meally, Robert G. (toim). 1998. The Jazz Cadence of American Culture. New York: Columbia University Press.

PL 1932 = Uus salongitants "Eesti valss". Päevaleht, 15. oktoober.

PL 1939 = Täna mängib Estonias Šoti noorte orkester. Päevaleht. 1. september.

Porter, Lewis \& Ullman, Michael \& Hazel, Edward 1992. Jazz: From Its Origins to the Present. New Jersey: Prentice Hall Englewood Cliffs.

PM 1943 = Vana kultuuritegelase juubel. Postimees. 13. märts.

Raudla, Heiki 1993. Viljandi tantsumuusikast sajandivahetusest kuni neljakümnendate aastateni. Raudla, Heiki et alii (koost). Sakala kalender. Viljandi:Viljandi Linnavalitsus, lk 130-135.

RL 1926 = Õpivad tantsima... Rahvaleht. 9. märts.

Saretok, Valve 1957. Läbi uduliniku II. Valga Tütarlaste Gümnaasiumis. Toronto: Orto.

Saviauk, Jaan 1983. Leningradi eestlaste muusikaelust. Kuusk, Priit (koost). Muusikalisi lehekülgi III. Tallinn: Eesti Raamat.

Starr, Frederick S. 1983. Red \& Hot. The Fate of Jazz in the Soviet Union 1917-1980. New York: Oxford University Press.

Tampere, Herbert 1975. Eesti rahvapillid ja rahvatantsud. Tallinn: Eesti Raamat.

Teder, Juhan 1984. Pikad künnivaod. Kultuur ja Elu 11, lk 31-34.

Tõnurist, Igor 1996. Pillid ja pillimäng eesti külaelus. Scripta ethnologica 1. Tallinn: Teaduste Akadeemia Kirjastus.

VK 1995 = Vastab Hendrik Juurikas - Võru muusikaelu Grand Old Man. Viruskundra $11, \mathrm{lk} 4-5$.

Whiteman, Paul 1926. Jazz. New York: J. H. Sears \& Company, Inc. 


\title{
Summary
}

\section{Relationship between Jazz and Ethnic Music in Estonia in the First Half of the $2^{\mathrm{TH}}$ Century}

\author{
Tiit Lauk
}

Key words: acculturation, haitarijazz, jazz, swing, The Murphy Band, village bands, village jazz

This article covers an underexplored facet in the Estonian cultural history - expansion of jazz music into our cultural space and facts related to this, focussing on mutual influences between jazz and Estonian ethnic culture. Although we have been long accustomed to the fact that jazz music is an inseparable part of our culture scene, debates on what is jazz are still ongoing and there does not yet exist an overall and widely accepted definition. The relations between village bands and jazz are studied from the point of view of several acculturation theories.

The article presents an overview of the situation in the Estonian music culture in the 1920s when jazz appeared in Estonia. This was an extremely favourable moment for new development - the state and the people had recently liberated themselves, thus there existed a natural wish to get oneself free from the cultural pressure dictated by politics. It appears that in several places in the region south of the Tartu-ViljandiPärnu imaginary line people have tried to play jazz with village bands. This refers to the start-up of the acculturation process in this region between the local ethnic music and the afro-American jazz music, which had intruded into our cultural space. In order to understand the singularity of this phenomenon, the article examines in greater detail the type of ensemble called a village band in Estonia. While studying these village bands, it appeared that the village bands venturing to play jazz-like dance music were divided into two broader style-based groups. The article covers bands of both of these groups in greater detail, presenting an analysis of their makeup as well as their repertoires. Music played by those bands should be defined as Estonian(ethnic)-music-inspired jazz-like dance music (the first group) or jazz-inspired ethnic dance music (the second group). For a more specific classification the term "village jazz" could be used. For comparison, the article covers also haitarijazz - a symbiosis of jazz and ethnic music appearing in Finland in the 1920s-1930s. Recently more and more voices could be heard suggesting that jazz should be studied together with ethnic music, because the origin and development of jazz bear a number of common features with it.

As Rahvaleht (People's Newspaper) writes, Sergei Insarov, a well-known dance teacher together with his assistants Tamara Istomina and Viktor Reitel had trained almost 12,000 people to dance in five years in Narva, Pärnu, Rakvere, Paide, including rural areas (“Õpivad tantsima..."(Dance classes) Rahvaleht, 9 March 1926). 